\title{
Intestinal metabolism of sulfur amino acids
}

\author{
Caroline Bauchart-Thevret, Barbara Stoll and Douglas G. Burrin* \\ Department of Pediatrics, Baylor College of Medicine, USDA/ARS Children's Nutrition Research Center, \\ Houston, Texas 77030, USA
}

\begin{abstract}
The gastrointestinal tract (GIT) is a metabolically significant site of sulfur amino acid (SAA) metabolism in the body and metabolises about $20 \%$ of the dietary methionine intake which is mainly transmethylated to homocysteine and trans-sulfurated to cysteine. The GIT accounts for about $25 \%$ of the whole-body transmethylation and trans-sulfuration. In addition, in vivo studies in young pigs indicate that the GIT is a site of net homocysteine release and thus may contribute to the homocysteinaemia. The gut also utilises $25 \%$ of the dietary cysteine intake and the cysteine uptake by the gut represents about $65 \%$ of the splanchnic first-pass uptake. Moreover, we recently showed that SAA deficiency significantly suppresses intestinal mucosal growth and reduces intestinal epithelial cell proliferation, and increases intestinal oxidant stress in piglets. These recent findings indicate that intestinal metabolism of dietary methionine and cysteine is nutritionally important for intestinal mucosal growth. Besides their role in protein synthesis, methionine and cysteine are precursors of important molecules. $S$-adenosylmethionine, a metabolite of methionine, is the principal biological methyl donor in mammalian cells and a precursor for polyamine synthesis. Cysteine is the rate-limiting amino acid for glutathione synthesis, the major cellular antioxidant in mammals. Further studies are warranted to establish how SAA metabolism regulates gut growth and intestinal function, and contributes to the development of gastrointestinal diseases. The present review discusses the evidence of SAA metabolism in the GIT and its functional and nutritional importance in gut function and diseases.
\end{abstract}

Methionine: Cysteine: $S$-adenosylmethionine: Glutathione

\section{Introduction}

Increasing evidence indicates that sulfur amino acids, methionine and cysteine, are implicated in numerous biological functions and diseases, aside from their role in protein synthesis ${ }^{(1-3)}$. Methionine is an indispensable amino acid and is transmethylated intracellularly to homocysteine via $S$-adenosylmethionine (SAM), the principal biological methyl donor in mammalian cells and a precursor for polyamine synthesis ${ }^{(4)}$ (Fig. 1). Reduced SAM concentrations, as a consequence of low methionine intake or folate deficiency, mainly lead to a deregulation in DNA methylation and are implicated in various cancers, including colorectal cancer $^{(5,6)}$. Homocysteine is a sulfur-containing amino acid present in the blood and tissues but not incorporated into protein $^{(7)}$. Numerous clinical studies have shown that elevated plasma homocysteine levels are strongly associated with increased risk for several diseases, including CVD, stroke, Alzheimer's disease and osteoporosis ${ }^{(8-10)}$. Homocysteine can be converted into cysteine via cystathionine through the trans-sulfuration pathway, an irreversible process $^{(1)}$ (Fig. 1). Homocysteine can also be methylated back to methionine via the remethylation pathway (Fig. 1). The combination of transmethylation and remethylation pathways comprises the methionine cycle which occurs in most cells. However, the trans-sulfuration pathway has a limited tissue distribution and is restricted to the liver, kidney, intestine, pancreas and adrenals ${ }^{(3,11)}$. Cysteine is considered a semi-indispensable amino acid whose availability is dependent upon methionine intake ${ }^{(1)}$. However, dietary cysteine can satisfy a proportion of the sulfur amino acid requirement, the so-called cysteine-sparing effect on dietary methionine requirement ${ }^{(12)}$. Cysteine is a constituent amino acid of the tripeptide glutathione ( $\gamma$-Glu-Cys-Gly), the major cellular antioxidant in mammals, and serves also as a precursor for the synthesis of taurine, pyruvate, sulfate and hydrogen sulfide $\left(\mathrm{H}_{2} \mathrm{~S}\right)$ (Fig. 1).

Although the liver is usually considered as one of the major organs in the body that metabolises sulfur amino

Abbreviations: CBS, cystathionase $\beta$-synthase; CDO, cysteine dioxygenase; GIT, gastrointestinal tract; GSH, reduced glutathione; HMB, 2-hydroxy-(4-methylthio)butanoic acid; IBD, inflammatory bowel disease; MAT, methionine adenosyltransferase; MTA, methylthioadenosine; MTHFR, methylenetretrahydrofolate reductase; SAM, $S$-adenosylmethionine.

* Corresponding author: Dr Douglas G. Burrin, fax +1 713798 7057, email dburrin@bcm.tmc.edu 


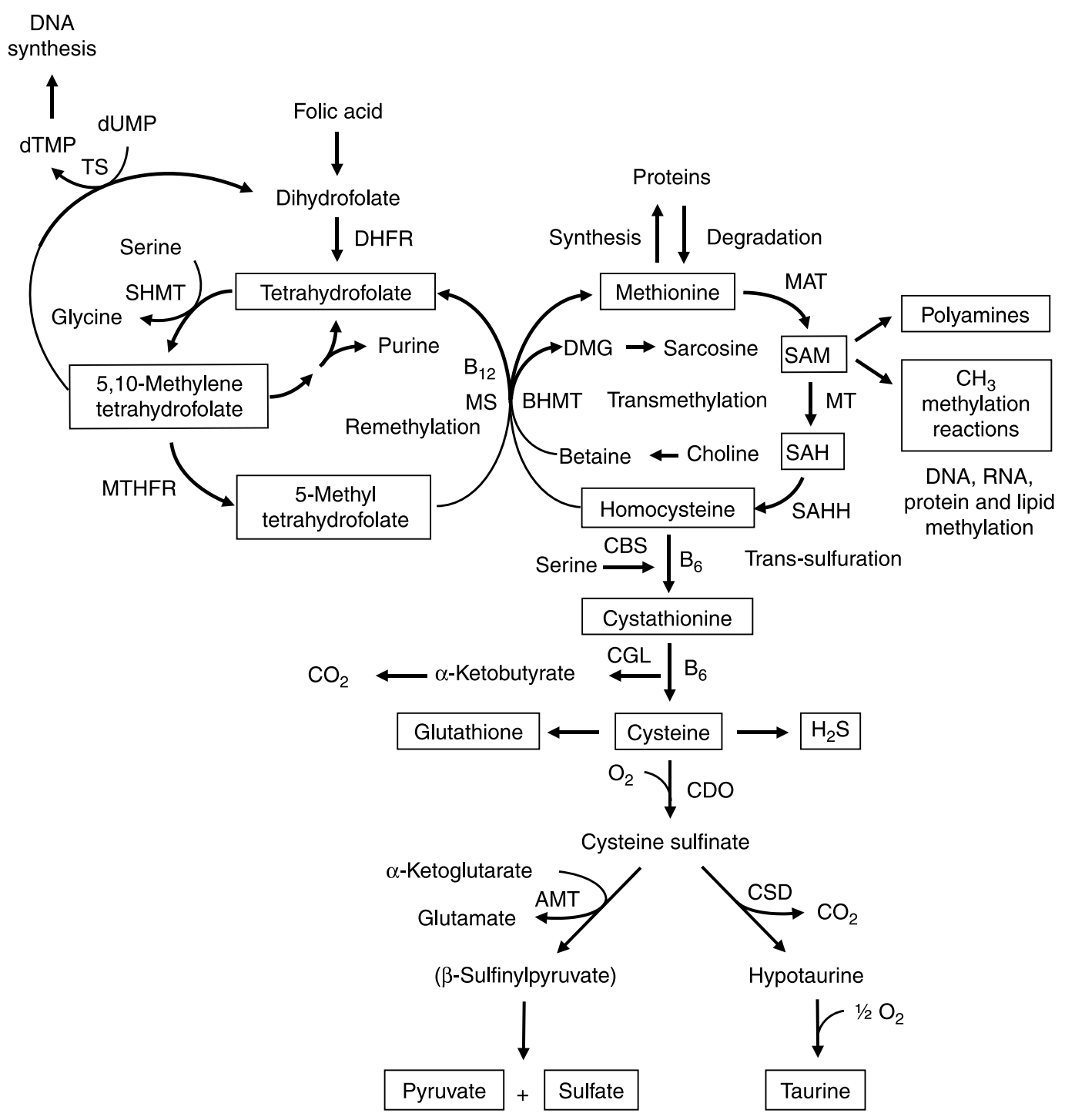

Fig. 1. Sulfur amino acid metabolism. AMT, aminotransferase; BHMT, betaine-homocysteine methyltransferase; CBS, cystathionine $\beta$-synthase; CDO, cysteine dioxygenase; CGL, cystathionine $\gamma$-lyase; CSD, cysteine sulfinate decarboxylase; DHFR, dihydrofolate reductase; DMG, dimethylglycine; dTMP, thymidylate; dUMP, deoxyuridylate; MAT, methionine adenosyltransferase; MS, methionine synthase; MT, methyl transferases; MTHFR, methylenetetrahydrofolate reductase, SAH, S-adenosylhomocysteine; SAHH, S-adenosylhomocysteine hydrolase; SAM, $S$-adenosylmethionine; SHMT, serine hydroxymethyltransferase; TS, thymidylate synthetase.

acids, the gastrointestinal tract (GIT), and especially the intestine, appears to be also a significant site of dietary sulfur amino acid metabolism. Several reports indicate that intestinal sulfur amino acid metabolism is nutritionally important for normal gut function and intestinal mucosal growth. Dysregulation in the intestinal sulfur amino acid metabolism leads to numerous complications and diseases. In the present review, we will discuss the evidence of sulfur amino acid metabolism in the GIT and its functional and nutritional importance in health and disease.

\section{Isotopic approaches to study sulfur amino acid metabolism}

The introduction of stable-isotope tracer methodology has enabled the measurement of sulfur amino acid metabolism in vivo in human subjects, including adults and infants.
Storch et al. ${ }^{(13,14)}$ were the first to explore sulfur amino acid metabolism in human subjects using a stable-isotope approach. Their model was based on the intravenous infusion of a doubly-labelled methionine isotopomer $\left[1-{ }^{13} \mathrm{C}\right.$; methyl- $\left.{ }^{2} \mathrm{H}_{3}\right]$ methionine to determine the wholebody methionine carboxyl and methyl fluxes which provided estimates of transmethylation, trans-sulfuration and remethylation rates (Fig. 2). These studies demonstrated the role of feeding, fasting and the sparing effect of cysteine on kinetics of methionine catabolism in man and they defined the relative recycling of methionine through the remethylation of homocysteine ${ }^{(14)}$. In their methionine kinetic calculations, Storch et al. used an estimate of the intracellular methionine isotopic enrichment based on the intracellular dilution of leucine estimated with plasma $\alpha$-ketoisocaproate enrichments observed by Matthews et al. ${ }^{(15)}$, yet this assumption does not reflect the true 


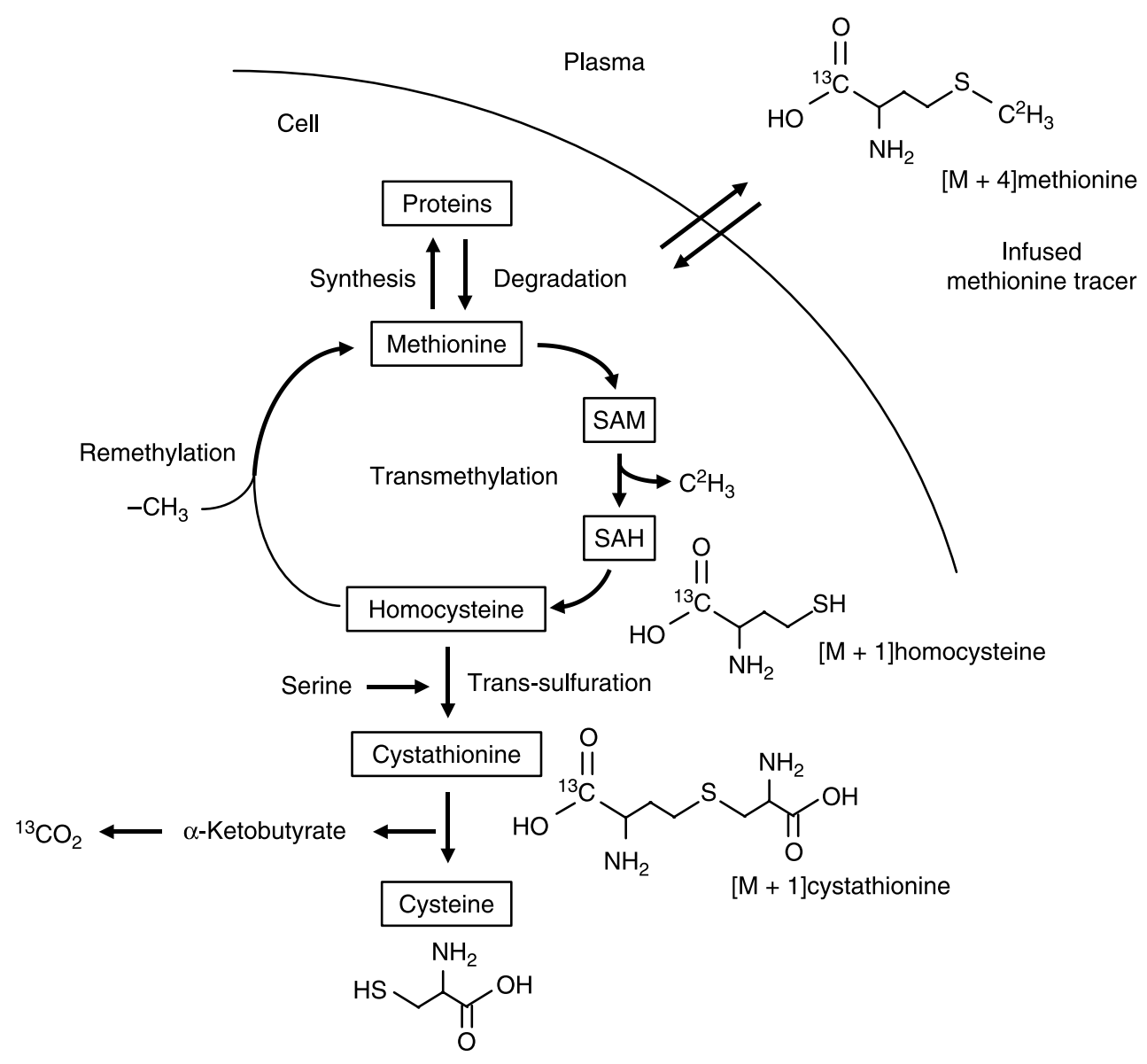

Fig. 2. Stable isotopic tracer model used by Storch et al. ${ }^{(14)}$. This model is based on the intravenous infusion of a methionine isotopomer $\left[1-{ }^{13} \mathrm{C}\right.$; methyl- $\left.{ }^{2} \mathrm{H}_{3}\right]$ methionine $[M+4]$. The $\left[{ }^{2} \mathrm{H}_{3}\right]$ methyl group is lost during transmethylation from $S$-adenosylmethionine (SAM) to $S$ adenosylhomocysteine $(\mathrm{SAH})$, whereas the $\left[{ }^{13} \mathrm{C}\right]$ carbon group is transferred to $\left[1-{ }^{13} \mathrm{C}\right]$ homocysteine $[\mathrm{M}+1],\left[1-{ }^{13} \mathrm{C}\right]$ cystathionine $[\mathrm{M}+1]$ and finally, oxidised to ${ }^{13} \mathrm{CO}_{2}$ via $\alpha$-ketobutyrate in the tricarboxylic acid cycle.

physiological effect of methionine metabolism. More recently, this model has been modified by MacCoss et al. ${ }^{(7)}$ and others using plasma homocysteine enrichments to correct the intracellular methionine enrichments, since plasma homocysteine can be derived only from intracellular homocysteine formed by methionine transmethylation. Consistent with other reports ${ }^{(16,17)}$, the rates of methionine kinetics were substantially higher after homocysteine correction than previous estimates.

Few other studies have used different isotopomers to study whole-body methionine metabolism. A complication of the measurement of homocysteine remethylation rate is that the reaction can be catalysed by two enzymic pathways. Homocysteine can be methylated back to methionine by the ubiquitously distributed methionine synthase using 5-methyltetrahydrofolate as a methyl donor, and also in a folate-independent pathway by betaine-homocysteine methyltransferase (Fig. 1), which is expressed only in the liver and the kidney ${ }^{(3)}$. To distinguish between the methyl groups transferred by the two homocysteine methyltransferases, Davis et al. ${ }^{(18)}$ used a combined isotopic approach of $\left[\mathrm{U}-{ }^{13} \mathrm{C}\right]$ methionine and $\left[3-{ }^{13} \mathrm{C}\right]$ serine. With this tracer combination, the remethylated methionine tracer, i.e. $\left[{ }^{13} \mathrm{C}_{4}\right]$ methionine, was measured separately from the $\left[{ }^{13} \mathrm{C}_{1}\right]$ methionine generated by the folate-dependent homocysteine remethylation pathway from $\left[3{ }^{13} \mathrm{C}\right]$ serine. Using this tracer model, they determined that serine is the predominant one-carbon donor for homocysteine remethylation in healthy females with adequate folate, vitamin $B_{12}$ and vitamin $\mathrm{B}_{6}$ nutritional status. The steady-state model of Storch et al. was also discussed by Hoffer ${ }^{(19)}$ who concluded that this model can not provide information about the type and the severity of metabolic blocks that cause, for instance, hyperhomocysteinaemia. Based on this appreciation, Shinohara et al. ${ }^{(20)}$ examined the remethylation of homocysteine after a single administration of $\left[{ }^{2} \mathrm{H}_{7}\right]$ methionine in rats under folate and/or choline (a precursor of betaine) deficiency. With a ${ }^{2} \mathrm{H}$ label in the methyl position, this model has the advantage to recognise directly the elimination of methionine and to determine the extent of homocysteine remethylation by measuring $\left[{ }^{2} \mathrm{H}_{7}\right]$ methionine, $\left[{ }^{2} \mathrm{H}_{4}\right]$ homocysteine, $\left[{ }^{2} \mathrm{H}_{4}\right]$ methionine and unlabelled methionine by GC-MS. Their results showed that plasma levels of remethylated methionine were influenced by choline deficiency rather than folate deficiency.

Important contributions to our knowledge of the dietary requirement for sulfur amino acids and the effect of cysteine on methionine requirement in man have resulted from recent 
studies using tracer isotopic approaches ${ }^{(12,21-23)}$. The ability of cysteine to provide a proportion of the total sulfur amino acid requirements in man, hence providing a sparing effect on methionine requirement, has been extensively debated $^{(12,21,23)}$. Many studies performed in animals have shown that more than $40 \%$ of the sulfur amino acid requirement can be met by dietary cysteine ${ }^{(12,24-28)}$. However, the cysteine-sparing effect on methionine requirement in adult human subjects was not found in a set of studies using methionine and cysteine tracers $^{(13,29-32)}$. In these human studies, the methionine and cysteine intake was based on the 1985 FAO, WHO and United Nations University recommendation of $13 \mathrm{mg} / \mathrm{kg}$ per $\mathrm{d}$, which has been recently found to be deficient for humans ${ }^{(33,34)}$. The failure to detect a cysteinesparing effect in those studies ${ }^{(13,29-32)}$ has been discussed by Ball et al. ${ }^{(12)}$ and appears to be related to the methionine intake below the minimum obligatory requirement, which has not been defined yet. More recent stable-isotope studies in human subjects, using indicator amino acid oxidation ${ }^{(35)}$ and $24 \mathrm{~h}$ indicator amino acid oxidation and indicator amino acid balance ${ }^{(22)}$ techniques to determine the sulfur amino acid requirement, have found a sparing effect of methionine requirement by cysteine with graded levels of methionine in the absence and presence of excess cysteine in the diet. These studies ${ }^{(22,35)}$ combined with earlier $\mathrm{N}$ balance studies ${ }^{(36-38)}$ provide evidence of a cysteine-sparing effect in man that ranges from 17 to $90 \%$. The sparing effect of cysteine on dietary methionine requirement appears to occur by reducing methionine catabolism through trans-sulfuration to cystathionine, which is related to a decrease in the concentration of cystathionase $\beta$-synthase (CBS), the enzyme that synthesises cystathionine from homocysteine (Fig. 1), and SAM (Fig. 1), a positive effector of the CBS enzyme $^{(39)}$. Most recently, it has been shown that when total sulfur amino acid needs are provided as methionine at $14 \mathrm{mg} / \mathrm{kg}$ per $\mathrm{d}$ in the presence of an adequate protein intake of $1 \mathrm{~g} / \mathrm{kg}$ per $\mathrm{d}^{(40)}$, extra cysteine does not increase the synthesis of erythrocyte glutathione, the major cellular antioxidant, in healthy adult humans ${ }^{(41)}$. Moreover, the cysteine-sparing effect on methionine requirement has been also estimated in parenterally and enterally fed piglets and the safe methionine intake with an excess of cysteine was determined to be 0.27 and $0.36 \mathrm{~g} / \mathrm{kg}$ per $\mathrm{d}$ in parenteral and enteral feeding, respectively ${ }^{(27)}$. The significant difference in methionine requirement between parenteral and enteral feeding indicates that the gut utilises about $28 \%$ of the total sulfur amino acid requirement ${ }^{(27)}$, suggesting an active metabolic role of the gut in the whole-body sulfur amino acid metabolism, although the cysteine-sparing effect is not dependent on first-pass metabolism in the gut.

\section{Evidence of intestinal sulfur amino acid metabolism}

In 1965, Mudd et al. ${ }^{(42)}$ were the first to show significant levels of three enzymes involved in the trans-sulfuration pathway, i.e. methionine adenosyltransferase (MAT), CBS and cystathionine $\gamma$-lyase, in rat small intestine mucosa, but at lower activities for one or more enzymes compared with the liver, pancreas and kidney. In 1972, Stegink \& Den Besten $^{(4)}$ then showed that splanchnic organs are an important site of transmethylation and trans-sulfuration of dietary methionine for the synthesis of cysteine in human adults. They found a twofold higher plasma cystine concentration in adults given a continuous cyst(e)ine-free nutrient solution for 2 weeks via the nasogastric route compared with the intravenous route. Since then, others studies have shown that total parenteral nutrition without cysteine results in low circulating levels of cystine in newborn infants ${ }^{(44)}$ and neonatal piglets ${ }^{(45)}$. In agreement with the study from Stegink \& Den Besten ${ }^{(43)}$, plasma cystine concentrations were higher in enterally than parenterally fed piglets administered methionine as the sole sulfur amino acid source ${ }^{(45)}$. These data suggest that the first-pass splanchnic metabolism is important for the synthesis of cysteine in neonates as well as adults.

Significant advancements in our understanding of splanchnic amino acid metabolism were derived from in vivo measurements of splanchnic organ balance ${ }^{(46)}$. Pig models have been extensively utilised to study human nutrition since they have similar physiology to man, especially gut physiology. Our studies in piglets showed that the net portal absorption of several indispensable amino acids, including methionine, was significantly less than $100 \%$ of the dietary intake, ranging from 40 to $70 \%{ }^{(47)}$. The importance of the gut was also demonstrated in studies where the whole-body methionine requirement was $30 \%$ greater in enterally fed than parenterally fed piglets ${ }^{(45,48)}$. Our recent study in infant piglets using the Storch et al. isotopic model indicates that the GIT metabolises $20 \%$ of dietary methionine intake which is mainly transmethylated to homocysteine and trans-sulfurated to cysteine ${ }^{(49)}$. The GIT accounts for about $25 \%$ of whole-body transmethylation and trans-sulfuration ${ }^{(49)}$. More direct evidence of intestinal sulfur amino acid metabolism was found in studies in rat by Finkelstein ${ }^{(50,51)}$, demonstrating that the small intestine possesses the enzymes necessary to metabolise methionine to cysteine, albeit at significantly lower activities than the liver. In our most recent piglet study, we also found significant enzymic activities of MAT, CBS and methionine synthase in the small intestine (jejunum and ileum $)^{(52)}$, enzymes that are involved in the methionine transmethylation, trans-sulfuration and remethylation pathways, respectively. All these studies provide compelling evidence of intestinal sulfur amino acid metabolism. However, recent studies in pigs found negligible catabolism of methionine in enterocytes ${ }^{(53,54)}$, suggesting that the metabolism of methionine in the intestine may result from the action of non-epithelial cells or luminal microbes in the intestinal mucosa.

Homocysteine, an intermediate metabolite formed during the metabolism of methionine to cysteine (Fig. 1), plays an important physiological role, since a dysregulation in homocysteine metabolism, leading to an elevated homocysteine plasma concentration, has been associated with an increased risk of CVD, stroke, Alzheimer's disease and osteoporosis $^{(8-10)}$. In our study in infant piglets, we demonstrated that the GIT is a site of net homocysteine release into the body ${ }^{(49)}$. A recent study performed on female rats investigated tissue homocysteine metabolism using stable-isotope approaches and tried to assess the contribution of individual tissues to plasma homocysteine 
by measuring the isotopic enrichment ${ }^{(55)}$. Interestingly, in contrast with previous studies ${ }^{(56,57)}$, they did not find a dominant role for the liver as a source of plasma homocysteine. Other tissues with higher intracellular homocysteine enrichments than in the plasma, including the small intestine, may also contribute to the homocysteinaemia $^{(55)}$.

As regards cysteine in the GIT, studies in pigs indicate that less than $100 \%$ of dietary cysteine appears in the portal blood, suggesting intestinal utilisation of cysteine ${ }^{(47,58)}$. The first step in cysteine catabolism is its conversion to cysteine sulfinate via the enzyme cysteine dioxygenase (CDO) (Fig. 1). The cysteine sulfinate is then either decarboxylated via cysteine sulfinate decarboxylase to produce hypotaurine, which is further oxidised to taurine via a poorly understood mechanism, or transaminated to the putitative intermediate $\beta$-sulfinylpyruvate that spontaneously decomposes to pyruvate and sulfate ${ }^{(59)}$ (Fig. 1). Rodent studies with ${ }^{14} \mathrm{C}$ labelled cysteine showed significantly higher oxidation when given via the intragastric $(70 \%)$ than the intraperitoneal $(41 \%)$ route, suggesting that nearly half of the wholebody cysteine oxidation occurs in splanchnic tissues ${ }^{(60)}$. More importantly, subsequent work demonstrated that rat enterocytes extensively metabolise cysteine via CDO to cysteine sulfinate ${ }^{(61)}$. This is in accordance with the expression of the murine CDO gene in the small intestine ${ }^{(62)}$. In contrast to rodent studies, our recent studies in infant pigs showed that the fractional whole-body oxidation of enteral cysteine $(22 \%)$ is lower than parenteral cysteine $(35 \%)^{(63)}$. We also found that splanchnic tissues (liver and gut) utilise about $40 \%$ of dietary cysteine intake in first-pass metabolism $^{(63)}$. Intestinal absorption was the major metabolic fate of dietary cysteine, representing $75 \%$ intake, indicating that the gut utilises $25 \%$ of the dietary cysteine intake $^{(63)}$. We also determined that cysteine gut uptake represents about $65 \%$ of the splanchnic first-pass uptake ${ }^{(63)}$. In addition, our results in pigs suggest that gut tissues consume a substantial proportion of dietary splanchnic cysteine metabolism via non-oxidative pathways ${ }^{(63)}$. We postulate that glutathione synthesis is a major non-oxidative metabolic fate for cysteine in the gut. Consistent with this, in vivo rodent studies with intravenous infusion of $\left[{ }^{15} \mathrm{~N}\right]$ cysteine indicate that an important metabolic fate of cysteine in the gut is incorporation into glutathione ${ }^{(64)}$.

Taurine is also another endproduct of cellular cysteine catabolism $^{(1)}$ (Fig. 1) and we recently found that taurine is produced by the small intestine in piglets ${ }^{(52)}$. Along with glutathione and cysteine, taurine plays an important role in the antioxidant function in the body ${ }^{(65)}$, especially in the intestine which is constantly exposed to endogenous and exogenous diet-derived oxidants. Moreover, among the numerous other physiological functions of taurine (i.e. osmoregulation, retinal and cardiac function, diabetes modulator, hepatoprotection, neuroprotection $\left.{ }^{(66,67)}\right)$, taurine is also involved in bile acid conjugation ${ }^{(67)}$. Bile acids are essential for intestinal digestion and absorption of lipids. In a recent study in adult patients with short-bowel syndrome ${ }^{(68)}$, long-term parenteral nutrition was associated with an impaired tauro-conjugation of bile acids (enterohepatic pool) and a low biliary taurine concentration despite the long-term taurine intravenous supplementation, suggesting a partition between the systemic and the enterohepatic taurine pools. This finding suggests that the intestine plays an important role in providing taurine to the liver. Besides the fact that the majority of the intestinal taurine pool is derived from the diet and absorbed by the gut, some taurine might also come from endogenous synthesis in the gut from cysteine since CDO expression has been found in rodent small intestine ${ }^{(59,62)}$. Moreover, we also found a decrease in taurine concentration in the ileum of piglets enterally fed a sulfur amino acid-free diet compared with a complete diet ${ }^{(52)}$, suggesting an intestinal synthesis of taurine from methionine and cysteine.

Catabolism of cysteine can also occur by desulfuration reactions that cleave the sulfur from cysteine to produce $\mathrm{H}_{2} \mathrm{~S}$ (Fig. 1) via multiple pathways, mainly through CBS and cystathionine $\gamma$-lyase activity ${ }^{(1,69)} \cdot \mathrm{H}_{2} \mathrm{~S}$ has been found to be produced by the ileum ${ }^{(70)}$ and the colon ${ }^{(71)}$ in rodents. $\mathrm{H}_{2} \mathrm{~S}$ is a gas that has been reported to exert anti-inflammatory ${ }^{(72)}$, relaxant ${ }^{(73,74)}$, prosecretory $^{(75)}$ and antinociceptive ${ }^{(76)}$ effects in the GIT. Factors that influence sulfur amino acid metabolism can also affect the production of $\mathrm{H}_{2} \mathrm{~S}$. Sulfur amino acid metabolism is regulated through the balance of production and disposal of cellular homocysteine and cysteine. Therefore, the release of homocysteine and $\mathrm{H}_{2} \mathrm{~S}$ by the gut depends on the methionine utilisation by the gut, which then may have an impact on peripheral physiology. For example, a recent study in rats demonstrated that liver endothelial dysfunction caused by hyperhomocysteinaemia was reversed by exogenous $\mathrm{H}_{2} \mathrm{~S}^{(77)}$.

Studies on ruminants also showed kinetic evidence of methionine metabolism, i.e. transmethylation, remethylation and trans-sulfuration in the GIT $^{(78,79)}$. Recent studies in lambs using stable-isotopic approaches demonstrated that the GIT is capable of methionine synthesis from the dietary methionine hydroxy analogue, namely 2-hydroxy(4-methylthio)butanoic acid (HMB) ${ }^{(80,81)}$. The methionine hydroxy analogue HMB is a synthetic source of methionine that is commonly added to commercial animal diets to ensure that the nutritional requirement for this essential amino acid is satisfied. The biochemical conversion of HMB to methionine involves two enzymic steps (Fig. 3). The first reaction is a stereospecific oxidation involving two enzymes: a peroxisomal L-2-hydroxy acid oxidase (L-HAOX) and a mitochondrial D-2-hydroxy acid dehydrogenase (D-HADH),

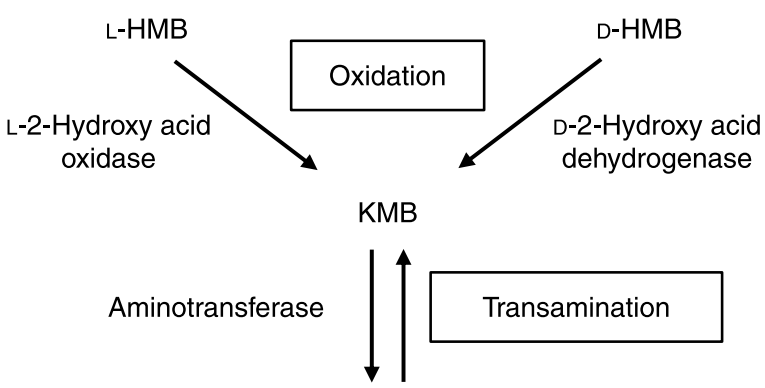

L-Methionine

Fig. 3. Metabolic pathway for the conversion of 2-hydroxy(4-methylthio)butanoic acid (HMB) to L-methionine. KMB, 2-keto(4-methylthio)butanoic acid. 
which catalyses the oxidation of L-HMB and D-HMB, respectively, into 2-keto-(4-methylthio)butanoic acid ${ }^{(82)}$. The second reaction is the transamination of 2-keto(4-methylthio)butanoic acid to L-methionine. This reaction is ubiquitous and does not constitute a limiting step in the metabolic conversion of DL-HMB to L-methionine ${ }^{(83)}$. However, the specific L-HAOX activity has been found in chicken liver and kidney ${ }^{(82,84)}$, rat liver ${ }^{(85)}$, pig kidney ${ }^{(86)}$ and also in liver, kidney and ruminal epithelia in sheep ${ }^{(87)}$, whereas the D-HADH has been detected in numerous tissues in chickens, including liver, kidney, skeletal muscle, intestine, pancreas, spleen and brain ${ }^{(82)}$, and in liver, kidney and ruminal epithelia in sheep ${ }^{(87)}$. Studies in lambs showed that more than $85 \%$ of the $\left[1-{ }^{13} \mathrm{C}\right] \mathrm{HMB}$ infused directly into the abomasum was absorbed into the portal vein and substantial enrichment of $\left[1-{ }^{13} \mathrm{C}\right]$ methionine occurred in the small- and large-intestinal tissues ${ }^{(80,81)}$. Moreover, recent studies in chickens have also demonstrated the capacity of the small intestine for significant HMB conversion to methionine ${ }^{(88,89)}$. It is now well established that HMB is a safe and efficacious precursor of methionine in chicks ${ }^{(90,91)}$. Although it still remains unknown whether the human GIT is capable of methionine synthesis from HMB, DL-HMB is currently used as an enteral product (Ketosteril ${ }^{\circledR}$, Fresenius Kabi), a mixture of ketoacids and amino acids, in conjunction with a low-protein diet, for patients suffering from renal insufficiency ${ }^{(91,92)}$.

\section{Sulfur amino acids and intestinal mucosal growth and function}

\section{Methionine, cysteine and glutathione}

The intestinal epithelium is one of the most dynamic sites of cell turnover in mammals ${ }^{(93)}$. Its growth status can be modulated by various stimuli, accompanied by corresponding changes in subepithelial mucosa. Total parenteral nutrition is commonly associated with a decrease in crypt cell proliferation and epithelial renewal rate ${ }^{(94)}$. Our results in piglets indicate that the minimal enteral nutrient intake necessary to increase mucosal mass was $40 \%$ of total nutrient intake, whereas $60 \%$ of enteral nutrition was necessary to sustain normal mucosal proliferation and growth $^{(95)}$. We recently demonstrated that a sulfur amino acid-free diet administered enterally to piglets for $7 \mathrm{~d}$ led to a reduced intestinal mucosal growth associated with villus atrophy, reduced epithelial cell proliferation, lower goblet cell number and diminished small-intestinal redox capacity ${ }^{(52)}$. Moreover, using $\left[1-{ }^{13} \mathrm{C}\right.$-methyl- $\left.{ }^{2} \mathrm{H}_{3}\right]-$ methionine and $\left[{ }^{15} \mathrm{~N}\right]$ cysteine tracer approaches, we also found an alteration in methionine metabolism under sulfur amino acid-deficient conditions at both whole-body and intestinal levels, where the methionine pool was preserved for protein synthesis by up-regulation of homocysteine remethylation and suppression of trans-sulfuration ${ }^{(52)}$. The suppression of trans-sulfuration contributed to the diminished cellular cysteine and glutathione concentrations and increased oxidant stress, which seemed to preferentially affect intestinal growth, especially in the jejunum ${ }^{(52)}$.

Evidence suggests that intracellular redox status plays an important role in the control of intestinal epithelial cell proliferation and apoptosis where increased oxidant stress and redox imbalance suppress cell proliferation and induce apoptosis $^{(96-99)}$. Glutathione $(\gamma$-Glu-Cys-Gly) is the major low-molecular-weight thiol in the cells that controls cellular thiol/disulfide redox state ${ }^{(100)}$ and serves as a major reservoir for cysteine ${ }^{(1)}$. Reduced glutathione $(\mathrm{GSH})$ is a ubiquitous tripeptide present in high concentration in tissue, especially in the intestine ${ }^{(101)}$. Cellular GSH homeostasis is maintained through de novo synthesis from precursor sulfur amino acids methionine and cysteine, regeneration from its oxidised form glutathione disulfide (GSSG), and uptake of extracellular intact GSH via $\mathrm{Na}^{+}$-dependent transport systems $^{(101)}$. Maintaining normal GSH concentration is essential to most tissues, especially the intestine, which is constantly challenged by luminal toxins and oxidants derived from the diet as well as endogenous generated reactive oxygen species. Indeed, a marked depletion of GSH, induced by buthionine sulfoximine, was shown to result in severe degeneration of jejunal and colonic epithelial cells in mice and this intestinal damage seemed to be prevented by concomitant GSH administration ${ }^{(102)}$. However, the notion of an essential need of GSH for cell growth appeared to be controversial ${ }^{(103)}$. Changes in the extracellular cysteine/cystine redox status per se have been shown to mediate proliferative signalling that is independent of the intracellular GSH/GSSG in colon cancer cells ${ }^{(104,105)}$. Thus, all these findings strongly suggest that sulfur amino acids methionine and cysteine play a key role in intestinal mucosal growth associated with a regulated redox status, and intestinal epithelial cell function.

\section{S-adenosylmethionine in methylation reactions and polyamine synthesis}

SAM has emerged as a key regulator of metabolism, proliferation, differentiation, apoptosis and cell death ${ }^{(106)}$. SAM is synthesised from methionine and ATP only by MAT (Fig. 4), which exists through three distinct isoforms (i.e. MAT I, MAT II and MAT III) ${ }^{(4)}$ that are the products of two different genes (i.e. MATIA and MAT2A) ${ }^{(107)}$. The gene $M A T 1 A$ encodes the $\alpha 1$ catalytic subunit, which organises into dimers (MAT III) or tetramers (MAT I). The gene $M A T 2 A$ encodes for the $\alpha 2$ catalytic subunit in the MAT II isoform. A third gene, MAT2 $\beta$, encodes for a $\beta$ regulatory subunit that regulates the activity of MAT II by lowering the inhibition constant $\left(K_{i}\right)$ for SAM and the Michaelis constant $\left(K_{m}\right)$ for methionine ${ }^{(108)}$. MAT1A is expressed mostly in adult liver, whereas $M A T 2 A$ is widely distributed. MAT2A is also expressed by fetal liver but is replaced by MAT1A during development ${ }^{(109)}$. Although MAT isoenzymes catalyse the same reaction, they are differentially regulated by their product, SAM. SAM maintains MAT1A expression in hepatocytes, but inhibits MAT2A expression ${ }^{(4)}$. In mammalian liver, MAT1A is a marker for the differentiated or mature liver phenotype, while $M A T 2 A$ is a marker for rapid growth and dedifferentiation ${ }^{(109)}$. The properties of mammalian MAT isoforms are summarised in Table 1. Few studies have examined the expression of MAT in intestinal tissues, yet the expression of the MAT2A gene and MAT II protein has been confirmed in human and mouse colonic tissue ${ }^{(110,111)}$. We recently confirmed MAT activity in piglet 


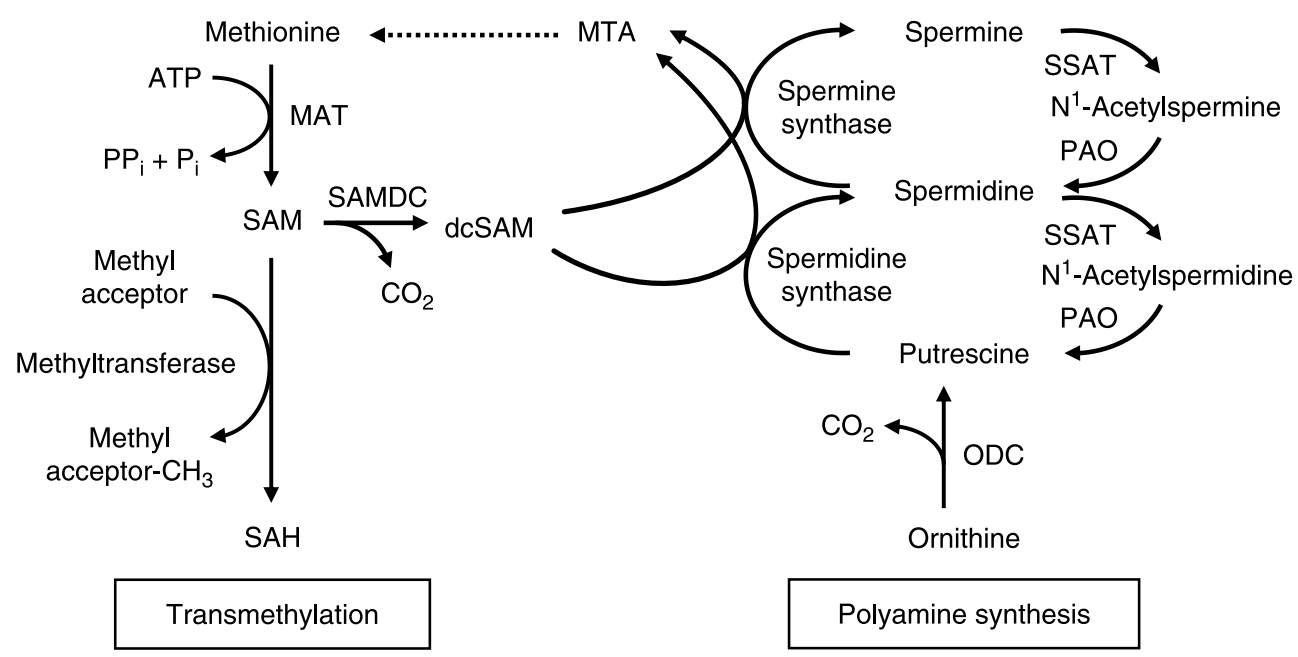

Fig. 4. S-adenosylmethionine (SAM) metabolic pathways: transmethylation and polyamine synthesis. dcSAM, decarboxylated $S$-adenosylmethionine; MAT, methionine adenosyltransferase; MTA, methylthioadenosine; SAH, S-adenosylhomocysteine; SAMDC, S-adenosylmethionine decarboxylase; ODC, ornithine decarboxylase; PAO, polyamine oxidase; SSAT, spermidine/spermine $\mathrm{N}^{1}$-acetyltransferase; $4 \cdots .$. , methionine salvage pathway.

small intestine ${ }^{(52)}$. MAT2A expression has been shown to be up-regulated by growth factors, such as epidermal growth factor, insulin-like growth factor-1 and leptin, in colorectal cancer cells HT-29 and RKO and its inhibition using RNAi led to cell death ${ }^{(111)}$. In addition, Chen et al. ${ }^{(11)}$ also demonstrated that SAM and its metabolite methylthioadenosine (MTA) (Fig. 4) are able to down-regulate MAT2A gene expression at high doses. These findings clearly indicate that MAT2A gene expression is critical for cell survival where SAM appears as a key role in the regulation of intestinal cell proliferation.

Besides its role as a constitutive precursor for protein synthesis, the role of methionine as a precursor for SAM synthesis may have greater regulatory importance for cell function and survival given its singular role in methylation reactions and control of gene expression. Once SAM is produced, it can be processed via two pathways, namely transmethylation or polyamine synthesis (Fig. 4). SAM is the major biological methyl group donor for a variety of methyltransferases, resulting in the methylation of substrates such as nucleic acids (DNA, RNA), proteins and lipids ${ }^{(112)}$, as well as the synthesis of small molecules (for example, creatine, phosphatidylcholine, adrenaline), modification of xenobiotics (for example, thiols, arsenite) and inactivation of neurotransmitters (for example, adrenaline, noradrenaline, dopamine $)^{(113)}$. DNA methylation is a major epigenetic modification of the genome that regulates crucial aspects of its function during development and in adults, including imprinting and $\mathrm{X}$-chromosome inactivation ${ }^{(114)}$. In mammalian cells, DNA methylation occurs mainly on cytosine residues at the $\mathrm{C}_{5}$ position within $\mathrm{CpG}$ dinucleotides to form 5-methylcytosine and this reaction is carried out by two important classes of DNA methyltransferases (DNMT). DNMT1 is essential for maintaining DNA-methylation patterns in proliferating cells, whereas DNMT3a and DNMT3b, two members of the second class of methyltransferases, are required for de novo methylation during embryonic development ${ }^{(115)}$. Few studies have examined the epigenetic mechanisms underlying normal gut development. Most of our knowledge on epigenetic involvement, especially methylation reactions, in intestinal metabolism and physiology comes from epigenetic dysregulation in gastrointestinal carcinogenesis, such as in colorectal cancer. The role of sulfur amino acid metabolism in colorectal cancer will be discussed further in the present review.

In addition to its role in methylation, SAM is also involved in the synthesis of polyamines (Fig. 4) which are known to play a key role in cell proliferation by regulating the expression of various growth-related genes $^{(116,117)}$. The intestinal epithelium is one of the most rapidly proliferating tissues in the body and, therefore, has a high demand for polyamines ${ }^{(118)}$. Several studies have demonstrated that polyamines stimulate normal intestinal epithelial cell proliferation and are required for the maintenance of mucosal integrity ${ }^{(118,119)}$. Very few studies have investigated the role of SAM in intestinal cell growth

Table 1. Properties of mammalian methionine adenosyltransferase (MAT) isoforms (from Lu \& Mato ${ }^{(145)}$ )

\begin{tabular}{lllllrrr}
\hline $\begin{array}{l}\text { MAT } \\
\text { isoform }\end{array}$ & Gene & $\begin{array}{c}\text { Catalytic } \\
\text { subunit }\end{array}$ & $\begin{array}{c}\text { Regulatory } \\
\text { subunit }\end{array}$ & Structure & $K_{m}$ (methionine) $^{*}$ & $\begin{array}{c}\text { Inhibition } \\
\text { by SAM }\end{array}$ & $\begin{array}{c}\text { Tissue } \\
\text { localisation }\end{array}$ \\
\hline MAT I & MAT1A & $\alpha 1$ & No & $(\alpha 1)_{4}$ & $23 \mu \mathrm{M}-1 \mathrm{mM}$ & No & Liver, pancreas \\
MAT III & MAT1A & $\alpha 1$ & No & $(\alpha 1)_{2}$ & $215 \mu \mathrm{M}-7 \mathrm{mM}$ & No & Liver, pancreas \\
MAT II & MAT2A & $\alpha 2$ & $\mathrm{~B}($ MAT2 $\beta$ gene) & $(\alpha 2)_{\times} \beta_{\mathrm{y}}$ & $4-10 \mu \mathrm{M}$ & $\begin{array}{c}\text { Yes } \\
\text { Extrahepatic tissue, } \\
\text { fetal liver, HCC }\end{array}$
\end{tabular}

SAM, S-adenosylmethionine; HCC, hepatocellular carcinoma. ${ }^{*} K_{m}$ values differ depending on the purity of the enzyme. 


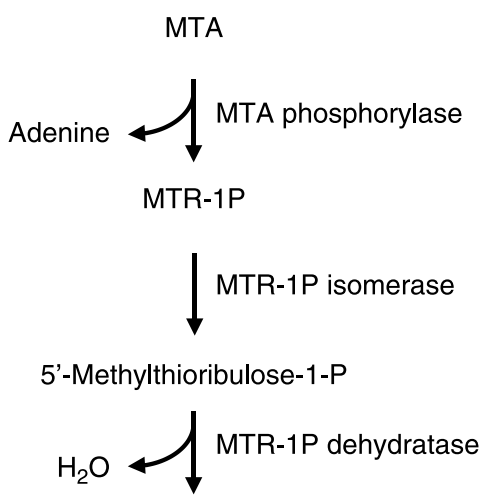

2,3-Dioxomethiopentane-1-P

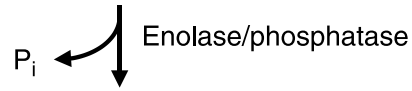

1,2-Dihydroxy 3-oxo methiopentene $\downarrow$ Dioxygenase

MTOB

MTOB transaminase

Methionine

Fig. 5. Methionine salvage pathway from $5^{\prime}$-methylthioadenosine (MTA). MTOB, 4-methylthio-2-oxobutanoic acid; MTR-1P, $5^{\prime}$-methylthioribose-1-P.

related to polyamine synthesis. SAM has been widely studied in hepatocytes since the liver is the major site of SAM synthesis and degradation ${ }^{(4)}$. A physiological increase in SAM has been reported to stimulate growth in liver cancer cells whereas a pharmalogical dose of SAM exerted a growth-inhibitory effect ${ }^{(120)}$. The effect of SAM at pharmalogical doses may be mediated by its metabolite MTA. SAM is very unstable and converts spontaneously to MTA in the polyamine synthesis (Fig. 4). In contrast to SAM, MTA has been shown to inhibit transmethylation and polyamine synthesis ${ }^{(121)}$. The removal of MTA by MTA phosphorylase is necessary both for the resynthesis of methionine (Fig. 5) and for polyamine synthesis, since MTA is a strong inhibitor of both spermine and spermidine synthases $^{(122)}$. In colon cancer cells, $6 \mathrm{~h}$ of MTA treatment $(1 \mathrm{mM})$ was shown to reduce polyamine level ${ }^{(111)}$. In addition, it was recently reported that SAM and MTA are able to induce apoptosis in colon cancer cell lines but not in normal colon epithelial cells ${ }^{(123)}$. These opposing effects of SAM and MTA on apoptosis in normal $v$. cancer cells have been also previously reported in hepatocytes ${ }^{(120)}$. However, the molecular mechanism of SAM and MTA on cell growth between colonocytes and hepatocytes may be different due to the presence of the MATIA gene in hepatocytes that is absent in intestinal cells and which is differently regulated by SAM (Table 1) ${ }^{(4)}$. Interestingly, the proapototic effect of MTA was not blocked by increased doses of polyamines in colon cancer cells $\mathrm{RKO}^{(123)}$. Polyamine depletion has been shown to both enhance and protect against apoptosis in a cell line- and stimulus-dependent manner ${ }^{(124)}$. Thus, all these data suggest that the concentration of SAM plays an important role in intestinal cell growth and apoptosis. A decrease in methionine intake or a deficiency in folate may disrupt methionine metabolism and have an impact on intestinal SAM pool and hence polyamine synthesis, which clearly emphasises the importance of dietary sulfur amino acid intake to maintain a normal intestinal growth.

\section{Sulfur amino acid metabolism and gastrointestinal diseases}

Considerable epidemiological evidence suggests that a lowfolate diet is associated with an increased risk of colorectal cancer $^{(125)}$. Like folate, choline and its oxidation product betaine are methyl-group donors that are involved in the remethylation of homocysteine to methionine (Fig. 1). Because homocysteine methylation by betaine via betainehomocysteine methyltransferase activity is confined to the liver and the kidney ${ }^{(3)}$, choline and betaine dietary intake may have less impact on the methylation of homocysteine in the colon than folate since methionine synthase that methylates homocysteine to methionine using 5-methyltetrahydrofolate as a methyl donor is ubiquitously distributed $^{(3)}$. One of the consequences of folate deficiency is SAM deficiency since folate is involved in the remethylation of homocysteine to methionine, the precursor of SAM (Fig. 1). However, folate supplementation can either prevent or exacerbate intestinal tumorigenesis, depending on the timing and dose of folate intervention ${ }^{(126)}$. This may be explained by the function of folate in nucleotide synthesis (Fig. 1) where rapidly proliferating tissues, including tumours, have an increased requirement for nucleotides. At present, based on lack of compelling supportive evidence on the potential tumour-promoting effect and presence of some adverse effects ${ }^{(127,128)}$, a recent review concludes that folate supplementation should not be recommended as a chemopreventive measure against colorectal cancer ${ }^{(129)}$. Interestingly, a low methionine intake, which decreases SAM levels and increases SAH levels, stimulates methylenetretrahydrofolate reductase (MTHFR) to irreversibly convert 5,10-methylenetetrahydrofolate to 5-methyltetrahydrofolate (Fig. 1) ${ }^{(130)}$. DNA methylation is an important epigenetic determinant in gene expression, in the maintenance of DNA integrity and stability, in chromatin modifications and in the development of mutations ${ }^{(131)}$. Aberrant DNA methylation, i.e. global genomic hypomethylation and hypermethylation of the promoter region of certain tumour-suppressor genes, has been implicated in colorectal carcinogenesis ${ }^{(132)}$. MTHFR is an important regulatory enzyme in the metabolism of folate and the genetic polymorphism of MTHFR can affect DNA methylation and influence the risk of colorectal cancer, particularly in the presence of a low-folate diet ${ }^{(133)}$. One of the most common functional polymorphisms of the MTHFR gene is the C677T polymorphism which results in an alanine-to-valine substitution at codon $222^{(134)}$. Individuals with the 677TT genotype (variant homozygotes) have no more than $30 \%$ of normal enzyme activity, while heterozygotes (CT) have $65 \%$ of normal enzyme activity ${ }^{(134)}$. A recent meta-analysis demonstrated that 
individuals with a homozygous variant of the MTHFR gene (677TT genotype) have a reduced risk of colorectal cancer $^{(135)}$. However, the beneficial effect of the $677 T T$ genotype was reported to be abolished when folate or methionine intake is low and/or with a high alcohol intake ${ }^{(136,137)}$.

Although there is an abundant literature on the role of folate in cancer risk, few studies have examined the role of SAM in the pathogenesis of colon cancer. One study examined MAT protein expression and activity in human colorectal cancer and found that MAT II activity is well correlated with the stage of colorectal tumour compared with normal tissue ${ }^{(110)}$. More recently, Chen et al. ${ }^{(111)}$ found higher SAM levels in human colon cancer specimens and polyps from Min (multiple intestinal neoplasia) mice, associated with an increase in MAT2A gene expression and MAT II protein level. In addition, they demonstrated that SAM and its metabolite MTA, at pharmacological doses, are able to down-regulate $M A T 2 A$ expression and to block the ability of growth factors (leptin, insulin-like growth factor-1 and epidermal growth factor) to induce $M A T 2 A$ expression and exert their mitogenic response in colorectal cancer cells HT-29 and RKO ${ }^{(111)}$. They also observed similar results in vivo in wild-type mice where SAM and MTA supplementation in drinking water for $6 \mathrm{~d}$ decreased MAT2A expression in proximal small intestine by $20 \%{ }^{(111)}$. The increased levels of intracellular SAM in cancerous colonocytes are likely to support polyamine synthesis required for growth and differentiation. However, high-dose SAM treatment was shown to inhibit growth and the effect is mediated by MTA ${ }^{(11)}$. Indeed, in contrast to SAM, MTA inhibits methylation and polyamine synthesis ${ }^{(138)}$. Therefore, like for folate, the dose of SAM supplementation may be a critical determinant in colorectal cancer susceptibility. In addition, due to their proapoptotic effect in colon cancer cells ${ }^{(123)}$, SAM and MTA may be attractive agents in the chemoprevention and treatment of colon cancer.

Homocysteine has been associated with the pathophysiology of inflammatory bowel disease (IBD). The two major forms of IBD, Crohn's disease and ulcerative colitis, represent chronic inflammatory disorders characterised by progressive destructive inflammation in the GIT. Hyperhomocysteinaemia has been consistently found in patients with IBD, as well as an increased level of homocysteine in colonic mucosa ${ }^{(139,140)}$. Elevated plasma and intestinal mucosal homocysteine concentration can result from either genetic defects affecting either the trans-sulfuration or remethylation pathways of homocysteine such as CBS deficiency or a polymorphism in MTHFR, or nutritional deficiencies of the vitamin cofactors (folate, vitamin $B_{12}$ and vitamin $\mathrm{B}_{6}$ ) required for homocysteine metabolism (Fig. 1) $^{(139,140)}$. However, no direct link has been established between homocysteine and IBD. Several studies suggest that homocysteine may promote inflammatory processes through oxidative stress ${ }^{(141)}$ and contribute to the inflammatory state of the mucosal endothelium through endoplasmic reticulum stress ${ }^{(142)}$. Although the aetiology of Crohn's disease and ulcerative colitis remains unknown, gut tissue injury is the result of an abnormal immune response and involves multiple non-immune cellular systems, including intestinal microvascular endothelial cells ${ }^{(143,144)}$. Whether increased circulating or local homocysteine is involved in these phenomena warrants further study.

\section{Conclusion}

An increasing body of evidence supports the metabolic significance of the GIT in sulfur amino acid metabolism. Recent in vivo studies show that the intestinal metabolism of dietary sulfur amino acids methionine and cysteine is nutritionally important for normal intestinal mucosal growth. However, it still remains unknown how sulfur amino acid metabolism regulates gut growth beyond its role as a precursor of protein biosynthesis. Methionine and cysteine also are the precursors of important molecules that may contribute to intestinal mucosal growth and gut function. SAM appears to be a key molecule that links three important metabolic pathways, i.e. transmethylation, transsulfuration and polyamine synthesis with MTA production. Epigenetic regulation of gene expression via modulation of DNA methylation may be the critical role of SAM. Further studies are warranted to determine the role of SAM and its metabolite MTA in methylation reactions in intestinal epithelial cells and how the regulation of their synthesis can affect intestinal cell survival and proliferation. Also, glutathione plays an important role in intestinal gut function due to, in part, its role in redox status. Thus, the availability of cysteine, the rate-limiting amino acid in glutathione synthesis, appears to be important for the maintenance of epithelial cell glutathione concentration and hence in the regulation of intestinal cell redox status. However, further investigation needs to be done to determine whether the increase in dietary cysteine intake may be an effective strategy to treat diseases related to oxidant injury in the GIT. Another potentially important metabolite of methionine cycle activity is homocysteine. As regards to IBD, further studies are warranted to establish whether the association between homocysteine and IBD is a causal link or a consequence of a poor nutritional status, mainly vitamin deficiencies (folate, vitamin $\mathrm{B}_{12}$ and $\mathrm{B}_{6}$ ). In the case of SAM and MTA, these metabolites may have important roles in both colonic epithelial cell survival and inflammation that could also be relevant to IBD and cancer.

\section{Acknowledgements}

The present review is a publication of the US Department of Agriculture, Agricultural Research Service (USDA/ARS) Children's Nutrition Research Center, Department of Pediatrics, Baylor College of Medicine and Texas Children's Hospital, Houston, TX. It was supported by federal funds from the USDA/ARS under cooperative agreement number 58-6250-6-001. The contents of this publication do not necessarily reflect the views or policies of the USDA, nor does mention of trade names, commercial products, or organisations imply endorsement by the US Government. C. B.-T. was supported by grants from Association pour le Développement de la Recherche en Nutrition (ADREN)/Société Francophone Nutrition Clinique et Métabolisme (SFNEP), Nutricia Research Foundation, and Société Française de Nutrition (SFN). 
We acknowledge the contribution of all authors in the writing of the present review.

The authors declare that they have no conflicts of interest.

\section{References}

1. Stipanuk MH (2004) Sulfur amino acid metabolism: pathways for production and removal of homocysteine and cysteine. Annu Rev Nutr 24, 539-577.

2. Shoveller AK, Stoll B, Ball RO, et al. (2005) Nutritional and functional importance of intestinal sulfur amino acid metabolism. J Nutr 135, 1609-1612.

3. Brosnan JT \& Brosnan ME (2006) The sulfur-containing amino acids: an overview. J Nutr 136, 1636S-1640S.

4. Mato JM, Corrales FJ, Lu SC, et al. (2002) $S$-adenosylmethionine: a control switch that regulates liver function. FASEB J 16, 15-26.

5. Kim YI (2005) Nutritional epigenetics: impact of folate deficiency on DNA methylation and colon cancer susceptibility. J Nutr 135, 2703-2709.

6. Giovannucci E, Rimm EB, Ascherio A, et al. (1995) Alcohol, low-methionine-low-folate diets, and risk of colon cancer in men. J Natl Cancer Inst 87, 265-273.

7. MacCoss MJ, Fukagawa NK \& Matthews DE (2001) Measurement of intracellular sulfur amino acid metabolism in humans. Am J Physiol Endocrinol Metab 280, E947-E955.

8. Zhou J \& Austin RC (2009) Contributions of hyperhomocysteinemia to atherosclerosis: causal relationship and potential mechanisms. Biofactors 35, 120-129.

9. Schulz RJ (2007) Homocysteine as a biomarker for cognitive dysfunction in the elderly. Curr Opin Clin Nutr Metab Care 10, 718-723.

10. Herrmann M, Peter SJ, Umanskaya N, et al. (2007) The role of hyperhomocysteinemia as well as folate, vitamin $\mathrm{B}(6)$ and $\mathrm{B}(12)$ deficiencies in osteoporosis: a systematic review. Clin Chem Lab Med 45, 1621-1632.

11. Zlotkin SH \& Anderson GH (1982) The development of cystathionase activity during the first year of life. Pediatr Res 16, 65-68.

12. Ball RO, Courtney-Martin G \& Pencharz PB (2006) The in vivo sparing of methionine by cysteine in sulfur amino acid requirements in animal models and adult humans. $J$ Nutr 136, 1682S-1693S.

13. Storch KJ, Wagner DA, Burke JF, et al. (1990) $\left[1{ }^{13} \mathrm{C}\right.$; methyl- ${ }^{2} \mathrm{H}_{3}$ ]methionine kinetics in humans: methionine conservation and cystine sparing. Am J Physiol 258, E790-E798.

14. Storch KJ, Wagner DA, Burke JF, et al. (1988) Quantitative study in vivo of methionine cycle in humans using [methyl- $\left.{ }^{2} \mathrm{H}_{3}\right]-$ and $\left[1{ }^{13} \mathrm{C}\right]$ methionine. Am J Physiol 255, E322-E331.

15. Matthews DE, Schwarz HP, Yang RD, et al. (1982) Relationship of plasma leucine and $\alpha$-ketoisocaproate during a L- $\left[1-{ }^{13} \mathrm{C}\right]$ leucine infusion in man: a method for measuring human intracellular leucine tracer enrichment. Metabolism 31, 1105-1112.

16. Tessari P, Kiwanuka E, Coracina A, et al. (2005) Insulin in methionine and homocysteine kinetics in healthy humans: plasma vs. intracellular models. Am J Physiol Endocrinol Metab 288, E1270-E1276.

17. Tessari P, Coracina A, Kiwanuka E, et al. (2005) Effects of insulin on methionine and homocysteine kinetics in type 2 diabetes with nephropathy. Diabetes 54, 2968-2976.

18. Davis SR, Stacpoole PW, Williamson J, et al. (2004) Tracer-derived total and folate-dependent homocysteine remethylation and synthesis rates in humans indicate that serine is the main one-carbon donor. Am J Physiol Endocrinol Metab 286, E272-E279.

19. Hoffer LJ (2004) Homocysteine remethylation and transsulfuration. Metabolism 53, 1480-1483.

20. Shinohara Y, Hasegawa H, Ogawa K, et al. (2006) Distinct effects of folate and choline deficiency on plasma kinetics of methionine and homocysteine in rats. Metabolism $\mathbf{5 5}$, 899-906.

21. Di Buono M, Wykes LJ, Cole DE, et al. (2003) Regulation of sulfur amino acid metabolism in men in response to changes in sulfur amino acid intakes. J Nutr 133, 733-739.

22. Kurpad AV, Regan MM, Varalakshmi S, et al. (2004) Effect of cystine on the methionine requirement of healthy Indian men determined by using the 24-h indicator amino acid balance approach. Am J Clin Nutr 80, 1526-1535.

23. Fukagawa NK (2006) Sparing of methionine requirements: evaluation of human data takes sulfur amino acids beyond protein. J Nutr 136, 1676S-1681S.

24. Baker DH, Clausing WW, Harmon BG, et al. (1969) Replacement value of cystine for methionine for the young pig. J Anim Sci 29, 581-584.

25. Graber G \& Baker DH (1971) Sulfur amino acid nutrition of the growing chick: quantitative aspects concerning the efficacy of dietary methionine, cysteine and cystine. J Anim Sci 33, 1005-1011.

26. Aguilar TS (1982) Studies in vivo on the methioninesparing effect of cysteine in rats. Arch Latinoam Nutr 32, 130-147.

27. Shoveller AK, Brunton JA, House JD, et al. (2003) Dietary cysteine reduces the methionine requirement by an equal proportion in both parenterally and enterally fed piglets. J Nutr 133, 4215-4224.

28. Baker DH (2006) Comparative species utilization and toxicity of sulfur amino acids. J Nutr 136, 1670S-1675S.

29. Hiramatsu T, Fukagawa NK, Marchini JS, et al. (1994) Methionine and cysteine kinetics at different intakes of cystine in healthy adult men. Am J Clin Nutr 60, 525-533.

30. Raguso CA, Ajami AM, Gleason R, et al. (1997) Effect of cystine intake on methionine kinetics and oxidation determined with oral tracers of methionine and cysteine in healthy adults. Am J Clin Nutr 66, 283-292.

31. Fukagawa NK, Yu YM \& Young VR (1998) Methionine and cysteine kinetics at different intakes of methionine and cysteine in elderly men and women. Am J Clin Nutr $\mathbf{6 8}$, 380-388.

32. Raguso CA, Regan MM \& Young VR (2000) Cysteine kinetics and oxidation at different intakes of methionine and cystine in young adults. Am J Clin Nutr 71, 491-499.

33. Di Buono M, Wykes LJ, Ball RO, et al. (2001) Total sulfur amino acid requirement in young men as determined by indicator amino acid oxidation with $\mathrm{L}-\left[1-{ }^{13} \mathrm{C}\right]$ phenylalanine. Am J Clin Nutr 74, 756-760.

34. Kurpad AV, Regan MM, Varalakshmi S, et al. (2003) Daily methionine requirements of healthy Indian men, measured by a 24-h indicator amino acid oxidation and balance technique. Am J Clin Nutr 77, 1198-1205.

35. Di Buono M, Wykes LJ, Ball RO, et al. (2001) Dietary cysteine reduces the methionine requirement in men. Am J Clin Nutr 74, 761-766.

36. Albanese AA, Holt LE Jr, Davis VI, et al. (1948) The sulfur amino acid requirement of the infant. Fed Proc 7, 141.

37. Rose WC \& Wixom RL (1955) The amino acid requirements of man. XIII. The sparing effect of cystine on the methionine requirement. J Biol Chem 216, 753-773. 
38. Reynolds MS, Steel DL, Jones EM, et al. (1958) Nitrogen balances of women maintained on various levels of methionine and cystine. J Nutr 64, 99-111.

39. Finkelstein JD, Martin JJ \& Harris BJ (1988) Methionine metabolism in mammals. The methionine-sparing effect of cystine. J Biol Chem 263, 11750-11754.

40. Humayun MA, Elango R, Ball RO, et al. (2007) Reevaluation of the protein requirement in young men with the indicator amino acid oxidation technique. Am J Clin Nutr 86, 995-1002.

41. Courtney-Martin G, Rafii M, Wykes LJ, et al. (2008) Methionine-adequate cysteine-free diet does not limit erythrocyte glutathione synthesis in young healthy adult men. J Nutr 138, 2172-2178.

42. Mudd SH, Finkelstein JD, Irreverre F, et al. (1965) Transsulfuration in mammals. Microassays and tissue distributions of three enzymes of the pathway. $J$ Biol Chem 240, 4382-4392.

43. Stegink LD \& Den Besten L (1972) Synthesis of cysteine from methionine in normal adult subjects: effect of route of alimentation. Science 178, 514-516.

44. Zlotkin SH, Bryan MH \& Anderson GH (1981) Cysteine supplementation to cysteine-free intravenous feeding regimens in newborn infants. Am J Clin Nutr 34, 914-923.

45. Shoveller AK, Brunton JA, Pencharz PB, et al. (2003) The methionine requirement is lower in neonatal piglets fed parenterally than in those fed enterally. $J$ Nutr 133, 1390-1397.

46. Stoll B \& Burrin DG (2006) Measuring splanchnic amino acid metabolism in vivo using stable isotopic tracers. J Anim Sci 84, Suppl., E60-E72.

47. Stoll B, Henry J, Reeds PJ, et al. (1998) Catabolism dominates the first-pass intestinal metabolism of dietary essential amino acids in milk protein-fed piglets. $J$ Nutr $\mathbf{1 2 8}$, 606-614.

48. Shoveller AK, House JD, Brunton JA, et al. (2004) The balance of dietary sulfur amino acids and the route of feeding affect plasma homocysteine concentrations in neonatal piglets. J Nutr 134, 609-612.

49. Riedijk MA, Stoll B, Chacko S, et al. (2007) Methionine transmethylation and transsulfuration in the piglet gastrointestinal tract. Proc Natl Acad Sci U S A 104, 3408-3413.

50. Finkelstein JD (2000) Pathways and regulation of homocysteine metabolism in mammals. Semin Thromb Hemost 26, 219-225.

51. Finkelstein JD (1990) Methionine metabolism in mammals. J Nutr Biochem 1, 228-237.

52. Bauchart-Thevret C, Stoll B, Chacko S, et al. (2009) Sulfur amino acid deficiency upregulates intestinal methionine cycle activity and suppresses epithelial growth in neonatal pigs. Am J Physiol Endocrinol Metab 296, E1239-E1250.

53. Chen LX, Yin YL, Jobgen WJS, et al. (2007) In vitro oxidation of essential amino acids by jejunal mucosal cells of growing pigs. Livest Sci 109, 19-23.

54. Chen L, Li P, Wang J, et al. (2009) Catabolism of nutritionally essential amino acids in developing porcine enterocytes. Amino Acids 37, 143-152.

55. Wilson FA, van den Borne JJ, Calder AG, et al. (2009) Tissue methionine cycle activity and homocysteine metabolism in female rats: impact of dietary methionine and folate plus choline. Am J Physiol Endocrinol Metab 296, E702-E713.

56. Stead LM, Brosnan ME \& Brosnan JT (2000) Characterization of homocysteine metabolism in the rat liver. Biochem J 350, 685-692.
57. Mudd SH, Brosnan JT, Brosnan ME, et al. (2007) Methyl balance and transmethylation fluxes in humans. Am J Clin Nutr 85, 19-25.

58. Bos C, Stoll B, Fouillet H, et al. (2003) Intestinal lysine metabolism is driven by the enteral availability of dietary lysine in piglets fed a bolus meal. Am J Physiol Endocrinol Metab 285, E1246-E1257.

59. Stipanuk MH, Ueki I, Dominy JE Jr, et al. (2009) Cysteine dioxygenase: a robust system for regulation of cellular cysteine levels. Amino Acids 37, 55-63.

60. Stipanuk MH \& Rotter MA (1984) Metabolism of cysteine, cysteinesulfinate and cysteinesulfonate in rats fed adequate and excess levels of sulfur-containing amino acids. $J$ Nutr 114, 1426-1437.

61. Coloso RM \& Stipanuk MH (1989) Metabolism of cyst(e)ine in rat enterocytes. J Nutr 119, 1914-1924.

62. Hirschberger LL, Daval S, Stover PJ, et al. (2001) Murine cysteine dioxygenase gene: structural organization, tissuespecific expression and promoter identification. Gene 277, $153-161$.

63. Cottrell J, Stoll B \& Burrin DG (2006) Kinetics of splanchnic ${ }^{13} \mathrm{C}$-cysteine metabolism in infant pigs. FASEB J 20, A9.

64. Malmezat T, Breuille D, Capitan P, et al. (2000) Glutathione turnover is increased during the acute phase of sepsis in rats. J Nutr 130, 1239-1246.

65. Atmaca G (2004) Antioxidant effects of sulfur-containing amino acids. Yonsei Med J 45, 776-788.

66. Huxtable RJ (1992) Physiological actions of taurine. Physiol Rev 72, 101-163.

67. Bouckenooghe T, Remacle C \& Reusens B (2006) Is taurine a functional nutrient? Curr Opin Clin Nutr Metab Care 9, $728-733$.

68. Schneider SM, Joly F, Gehrardt MF, et al. (2006) Taurine status and response to intravenous taurine supplementation in adults with short-bowel syndrome undergoing long-term parenteral nutrition: a pilot study. Br J Nutr 96, 365-370.

69. Li X, Bazer FW, Gao H, et al. (2009) Amino acids and gaseous signaling. Amino Acids 37, 65-78.

70. Zhao W, Ndisang JF \& Wang R (2003) Modulation of endogenous production of $\mathrm{H}_{2} \mathrm{~S}$ in rat tissues. Can J Physiol Pharmacol 81, 848-853.

71. Linden DR, Sha L, Mazzone A, et al. (2008) Production of the gaseous signal molecule hydrogen sulfide in mouse tissues. J Neurochem 106, 1577-1585.

72. Wallace JL (2007) Hydrogen sulfide-releasing anti-inflammatory drugs. Trends Pharmacol Sci 28, 501-505.

73. Teague B, Asiedu S \& Moore PK (2002) The smooth muscle relaxant effect of hydrogen sulphide in vitro: evidence for a physiological role to control intestinal contractility. Br J Pharmacol 137, 139-145.

74. Gallego D, Clave P, Donovan J, et al. (2008) The gaseous mediator, hydrogen sulphide, inhibits in vitro motor patterns in the human, rat and mouse colon and jejunum. Neurogastroenterol Motil 20, 1306-1316.

75. Schicho R, Krueger D, Zeller F, et al. (2006) Hydrogen sulfide is a novel prosecretory neuromodulator in the guinea-pig and human colon. Gastroenterology 131, $1542-1552$.

76. Distrutti E, Sediari L, Mencarelli A, et al. (2006) Evidence that hydrogen sulfide exerts antinociceptive effects in the gastrointestinal tract by activating KATP channels. J Pharmacol Exp Ther 316, 325-335.

77. Distrutti E, Mencarelli A, Santucci L, et al. (2008) The methionine connection: homocysteine and hydrogen sulfide exert opposite effects on hepatic microcirculation in rats. Hepatology 47, 659-667. 
78. Lobley GE, Connell A \& Revell D (1996) The importance of transmethylation reactions to methionine metabolism in sheep: effects of supplementation with creatine and choline. Br J Nutr 75, 47-56.

79. Lobley GE, Shen X, Le G, et al. (2003) Oxidation of essential amino acids by the ovine gastrointestinal tract. $\mathrm{BrJ}$ Nutr 89, 617-630.

80. Lobley GE, Wester TJ, Calder AG, et al. (2006) Absorption of 2-hydroxy-4-methylthiobutyrate and conversion to methionine in lambs. J Dairy Sci 89, 1072-1080.

81. Lobley GE, Wester TJ, Holtrop G, et al. (2006) Absorption and digestive tract metabolism of 2-hydroxy-4-methylthiobutanoic acid in lambs. J Dairy Sci 89, 3508-3521.

82. Dibner JJ \& Knight CD (1984) Conversion of 2-hydroxy4-(methylthio)butanoic acid to L-methionine in the chick: a stereospecific pathway. J Nutr 114, 1716-1723.

83. Rangel-Lugo M \& Austic RE (1998) Transamination of 2-oxo-4-[methylthio]butanoic acid in chicken tissues. Poult Sci 77, 98-104.

84. Ferjancic-Biagini A, Dupuis L, De Caro J, et al. (1995) In vitro oxidative decarboxylation of L-2-hydroxy4-methylthiobutanoic acid by L-2-hydroxy acid oxidase A from chicken liver. Biochimie 77, 249-255.

85. Langer BW Jr (1965) The biochemical conversion of 2-hydroxy-4-methylthiobutyric acid into methionine by the rat in vitro. Biochem J 95, 683-687.

86. Robinson JC, Keay L, Molinari R, et al. (1962) L- $\alpha-$ Hydroxy acid oxidases of hog renal cortex. $J$ Biol Chem 237, 2001-2010.

87. McCollum MQ, Vazquez-Anon M, Dibner JJ, et al. (2000) Absorption of 2-hydroxy-4-(methylthio)butanoic acid by isolated sheep ruminal and omasal epithelia. J Anim Sci 78, 1078-1083.

88. Martin-Venegas R, Soriano-Garcia JF, Vinardell MP, et al. (2006) Oligomers are not the limiting factor in the absorption of DL-2-hydroxy-4-(methylthio)butanoic acid in the chicken small intestine. Poult Sci 85, 56-63.

89. Martin-Venegas R, Geraert PA \& Ferrer R (2006) Conversion of the methionine hydroxy analogue DL-2hydroxy-(4-methylthio) butanoic acid to sulfur-containing amino acids in the chicken small intestine. Poult Sci 85, $1932-1938$.

90. Dilger RN, Kobler C, Weckbecker C, et al. (2007) 2-Keto4-(methylthio)butyric acid (keto analog of methionine) is a safe and efficacious precursor of L-methionine in chicks. J Nutr 137, 1868-1873.

91. Stipanuk MH (2007) The keto acid of methionine is a safe and efficacious substitute for dietary L-methionine: the answer from chick bioassays. J Nutr 137, 1844-1845.

92. Feiten SF, Draibe SA, Watanabe R, et al. (2005) Short-term effects of a very-low-protein diet supplemented with ketoacids in nondialyzed chronic kidney disease patients. Eur J Clin Nutr 59, 129-136.

93. Johnson LR (1988) Regulation of gastrointestinal mucosal growth. Physiol Rev 68, 456-502.

94. Burrin DG, Stoll B, Jiang R, et al. (2000) GLP-2 stimulates intestinal growth in premature TPN-fed pigs by suppressing proteolysis and apoptosis. Am J Physiol Gastrointest Liver Physiol 279, G1249-G1256.

95. Burrin DG, Stoll B, Jiang R, et al. (2000) Minimal enteral nutrient requirements for intestinal growth in neonatal piglets: how much is enough? Am J Clin Nutr 71, $1603-1610$.

96. Pias EK \& Aw TY (2002) Apoptosis in mitotic competent undifferentiated cells is induced by cellular redox imbalance independent of reactive oxygen species production. FASEB $J$ 16, 781-790.
97. Noda T, Iwakiri R, Fujimoto K, et al. (2001) Induction of mild intracellular redox imbalance inhibits proliferation of CaCo-2 cells. FASEB J 15, 2131-2139.

98. Jonas CR, Ziegler TR, Gu LH, et al. (2002) Extracellular thiol/disulfide redox state affects proliferation rate in a human colon carcinoma (Caco2) cell line. Free Radic Biol Med 33, 1499-1506.

99. Aw TY (2003) Cellular redox: a modulator of intestinal epithelial cell proliferation. News Physiol Sci 18, 201-204.

100. Jones DP (2002) Redox potential of GSH/GSSG couple: assay and biological significance. Methods Enzymol 348, 93-112.

101. Aw TY (1999) Molecular and cellular responses to oxidative stress and changes in oxidation-reduction imbalance in the intestine. Am J Clin Nutr 70, 557-565.

102. Martensson J, Jain A \& Meister A (1990) Glutathione is required for intestinal function. Proc Natl Acad Sci U S A 87, 1715-1719.

103. Tian J, Washizawa N, Gu LH, et al. (2007) Local glutathione redox status does not regulate ileal mucosal growth after massive small bowel resection in rats. $J$ Nutr 137, 320-325.

104. Noda T, Iwakiri R, Fujimoto K, et al. (2002) Exogenous cysteine and cystine promote cell proliferation in $\mathrm{CaCo}-2$ cells. Cell Prolif 35, 117-129.

105. Anderson CL, Iyer SS, Ziegler TR, et al. (2007) Control of extracellular cysteine/cystine redox state by HT-29 cells is independent of cellular glutathione. Am J Physiol Regul Integr Comp Physiol 293, R1069-R1075.

106. Martinez-Lopez N, Varela-Rey M, Ariz U, et al. (2008) $S$-adenosylmethionine and proliferation: new pathways, new targets. Biochem Soc Trans 36, 848-852.

107. Kotb M, Mudd SH, Mato JM, et al. (1997) Consensus nomenclature for the mammalian methionine adenosyltransferase genes and gene products. Trends Genet 13, $51-52$.

108. Halim AB, LeGros L, Geller A, et al. (1999) Expression and functional interaction of the catalytic and regulatory subunits of human methionine adenosyltransferase in mammalian cells. J Biol Chem 274, 29720-29725.

109. Lu SC \& Mato JM (2005) Role of methionine adenosyltransferase and $S$-adenosylmethionine in alcohol-associated liver cancer. Alcohol 35, 227-234.

110. Ito K, Ikeda S, Kojima N, et al. (2000) Correlation between the expression of methionine adenosyltransferase and the stages of human colorectal carcinoma. Surg Today 30 , $706-710$

111. Chen H, Xia M, Lin M, et al. (2007) Role of methionine adenosyltransferase $2 \mathrm{~A}$ and $S$-adenosylmethionine in mitogen-induced growth of human colon cancer cells. Gastroenterology 133, 207-218.

112. Chiang PK, Gordon RK, Tal J, et al. (1996) $S$-adenosylmethionine and methylation. FASEB $J \mathbf{1 0}$, 471-480.

113. Brosnan JT, da Silva R \& Brosnan ME (2007) Amino acids and the regulation of methyl balance in humans. Curr Opin Clin Nutr Metab Care 10, 52-57.

114. Reik W \& Dean W (2001) DNA methylation and mammalian epigenetics. Electrophoresis 22, 2838-2843.

115. Patra SK, Patra A, Rizzi F, et al. (2008) Demethylation of (cytosine-5-C-methyl) DNA and regulation of transcription in the epigenetic pathways of cancer development. Cancer Metastasis Rev 27, 315-334.

116. Moinard C, Cynober L \& de Bandt JP (2005) Polyamines: metabolism and implications in human diseases. Clin Nutr 24, 184-197. 
117. Bettuzzi S, Davalli P, Astancolle S, et al. (1999) Coordinate changes of polyamine metabolism regulatory proteins during the cell cycle of normal human dermal fibroblasts. FEBS Lett 446, 18-22.

118. McCormack SA \& Johnson LR (1991) Role of polyamines in gastrointestinal mucosal growth. Am J Physiol 260, G795-G806.

119. Wang JY (2007) Polyamines and mRNA stability in regulation of intestinal mucosal growth. Amino Acids 33, 241-252.

120. Ansorena E, Garcia-Trevijano ER, Martinez-Chantar ML, et al. (2002) S-adenosylmethionine and methylthioadenosine are antiapoptotic in cultured rat hepatocytes but proapoptotic in human hepatoma cells. Hepatology 35, 274-280.

121. Clarke SG (2006) Inhibition of mammalian protein methyltransferases by $5^{\prime}$-methylthioadenosine (MTA): a mechanism of action of dietary SAMe? In The Enzymes, vol. 24, pp. 467-493 [SG Clarke and F Tamanoi, editors]. New York: Elsevier/Academic Press.

122. Grillo MA \& Colombatto S (2008) $S$-adenosylmethionine and its products. Amino Acids 34, 187-193.

123. Li TW, Zhang Q, Oh P, et al. (2009) $S$-adenosylmethionine and methylthioadenosine inhibit cellular FLICE inhibitory protein expression and induce apoptosis in colon cancer cells. Mol Pharmacol 76, 192-200.

124. Seiler N \& Raul F (2005) Polyamines and apoptosis. J Cell Mol Med 9, 623-642.

125. Sanderson P, Stone E, Kim YI, et al. (2007) Folate and colorectal cancer risk. Br J Nutr 98, 1299-1304.

126. Kim YI (2003) Role of folate in colon cancer development and progression. J Nutr 133, 3731S-3739S.

127. Ulrich CM (2007) Folate and cancer prevention: a closer look at a complex picture. Am J Clin Nutr 86, 271-273.

128. Smith AD, Kim YI \& Refsum H (2008) Is folic acid good for everyone? Am J Clin Nutr 87, 517-533.

129. Kim YI (2008) Folic acid supplementation and cancer risk: point. Cancer Epidemiol Biomarkers Prev 17, 2220-2225.

130. Giovannucci E (2002) Epidemiologic studies of folate and colorectal neoplasia: a review. J Nutr 132, 2350S-2355S.

131. Jones PA \& Baylin SB (2002) The fundamental role of epigenetic events in cancer. Nat Rev Genet 3, 415-428.

132. Duthie SJ, Narayanan S, Sharp L, et al. (2004) Folate, DNA stability and colo-rectal neoplasia. Proc Nutr Soc 63, $571-578$.
133. Kim DH (2007) The interactive effect of methyl-group diet and polymorphism of methylenetetrahydrofolate reductase on the risk of colorectal cancer. Mutat Res 622, 14-18.

134. Frosst P, Blom HJ, Milos R, et al. (1995) A candidate genetic risk factor for vascular disease: a common mutation in methylenetetrahydrofolate reductase. Nat Genet $\mathbf{1 0}$, $111-113$.

135. Hubner RA \& Houlston RS (2007) MTHFR C677T and colorectal cancer risk: a meta-analysis of 25 populations. Int J Cancer 120, 1027-1035.

136. Chen J, Giovannucci E, Kelsey K, et al. (1996) A methylenetetrahydrofolate reductase polymorphism and the risk of colorectal cancer. Cancer Res 56, 4862-4864.

137. Ma J, Stampfer MJ, Giovannucci E, et al. (1997) Methylenetetrahydrofolate reductase polymorphism, dietary interactions, and risk of colorectal cancer. Cancer Res 57, 1098-1102.

138. Avila MA, Garcia-Trevijano ER, Lu SC, et al. (2004) Methylthioadenosine. Int J Biochem Cell Biol 36, 2125-2130.

139. Morgenstern I, Raijmakers MT, Peters WH, et al. (2003) Homocysteine, cysteine, and glutathione in human colonic mucosa: elevated levels of homocysteine in patients with inflammatory bowel disease. Dig Dis Sci 48, 2083-2090.

140. Danese S, Sgambato A, Papa A, et al. (2005) Homocysteine triggers mucosal microvascular activation in inflammatory bowel disease. Am J Gastroenterol 100, 886-895.

141. Papatheodorou L \& Weiss N (2007) Vascular oxidant stress and inflammation in hyperhomocysteinemia. Antioxid Redox Signal 9, 1941-1958.

142. Zhang C, Cai Y, Adachi MT, et al. (2001) Homocysteine induces programmed cell death in human vascular endothelial cells through activation of the unfolded protein response. J Biol Chem 276, 35867-35874.

143. Papa A, Scaldaferri F, Danese S, et al. (2008) Vascular involvement in inflammatory bowel disease: pathogenesis and clinical aspects. Dig Dis 26, 149-155.

144. Deban L, Correale C, Vetrano S, et al. (2008) Multiple pathogenic roles of microvasculature in inflammatory bowel disease: a Jack of all trades. Am J Pathol 172, 1457-1466.

145. Lu SC \& Mato JM (2008) $S$-adenosylmethionine in cell growth, apoptosis and liver cancer. $J$ Gastroenterol Hepatol 23, Suppl. 1, S73-S77. 